\title{
Crisis, desempleo y pobreza: análisis de trayectorias de vida y estrategias en el mercado laboral
}

\author{
María ARNAL \\ Departamento de Sociología V \\ Universidad Complutense de Madrid \\ m.arnal@cps.ucm.es \\ Lucila FINKEL \\ Departamento de Sociología IV \\ Universidad Complutense de Madrid \\ 1finkel@cps.ucm.es \\ Pilar PARRA \\ Departamento de Sociología IV \\ Universidad Complutense de Madrid \\ pparra@cps.ucm.es
}

Recibido: 29-01-2013

Aceptado: 19-04-2013

\section{RESUMEN}

A partir de la crisis financiera y económica que comienza en España en el año 2008, se ha acrecentado la precarización y la desregulación laboral. Mediante el uso de metodología cualitativa, este artículo estudia el efecto de la crisis sobre los trabajadores que han perdido su empleo y que apenas cuentan con recursos económicos. Con este fin se han identificado cuatro principales trayectorias laborales a partir de las cuales se analizan las distintas formas de percibir la crisis, el significado y las actitudes hacia el mercado laboral, y su vinculación potencial con procesos de mayor empobrecimiento. Igualmente, a partir de dichas trayectorias, se reconstruyen las distintas estrategias desplegadas para reinsertarse en el mercado laboral.

Palabras clave: trayectoria laboral, crisis, pobreza, precariedad, empleabilidad.

\section{Crisis, unemployment and poverty: analysis of life trayectories and strategies in the labour market}

\begin{abstract}
From the financial and economic crisis that is fully established in 2008 in Spain, precariousness and labor deregulation have largely increased. Using qualitative methodology, this article examines the impact of the crisis on workers who have lost their jobs and have scarce economic resources. To this end we have identified four main trajectories from which we analyze the different ways of perceiving the crisis, meanings and attitudes towards the labor market and its potential link with processes of greater impoverishment. Finally, from these trajectories we reconstruct various strategies that are deployed to get back into the labor market.
\end{abstract}

Keywords: labour trajectory, crisis, poverty, insecurity, employability. 


\section{REFERENCIA NORMALIZADA}

Arnal, M., Finkel, L., Parra, P. (2013). "Crisis, desempleo y pobreza: análisis de trayectorias de vida y estrategias en el mercado laboral”. Cuadernos de Relaciones Laborales. Vol. 31 Núm. 2, p. 281-311

SUMARIO: Introducción. 1. El impacto de la crisis. 2. El triunfo ideológico del neoliberalismo y la responsabilización del individuo: empleabilidad y activación. 3. La identificación de los perfiles de vulnerabilidad. 4. Trayectorias laborales: entre la desestabilización y la inestabilidad. 4.1. Trayectoria de los trabajadores/as estables desestabilizados. 4.2. Trayectoria de los trabajadores/as inestables desestabilizados. 4.3. Trayectoria de los trabajadores/as inestables estructurales. 4.4. Trayectoria de los trabajadores/as inestables coyunturales. 5. Significados y actitudes ante la crisis y el mercado laboral. Tendencias hacia un mayor empobrecimiento. 6. Estrategias de inserción en el mercado laboral. 7. Síntesis y conclusiones. 8. Bibliografía.

\section{Introducción}

La situación del mercado laboral español refleja los problemas derivados -entre otros factores- de una excesiva dependencia de sectores intensivos en mano de obra descualificada ${ }^{1}$, como la construcción o la hostelería, de una inversión en políticas de bienestar que continúa siendo menor que en el resto de países europeos (Navarro, 2009), de unas elevadas tasas de temporalidad y desempleo, superiores al resto de la Unión Europea -aún durante el período expansivo de la economía (1996-2007), cuando España crecía por encima de la media europea-, y por último, de la importancia de la economía sumergida ${ }^{2}$, incluso en los momentos de bonanza económica anteriores a la crisis (Arrazola et al., 2011).

En este contexto adverso, se analiza el efecto de la crisis sobre los trabajadores que han perdido su empleo desde el año 2008 hasta la actualidad. Más específicamente, el estudio de este colectivo se justifica no sólo por su falta de empleo, sino porque se encuentran en una situación de nueva pobreza al contar con escasos recursos económicos e ingresos, estar éstos próximos a su finalización, o no percibir ningún ingreso en absoluto. Cabe puntualizar que, en línea con distintos aportes realizados desde la Sociología, la situación de desempleo no implica por sí misma la existencia de vulnerabilidad social: un desempleado puede poseer un alto "poder social de negociación" (Villa, 1990) que le permite esperar su oportunidad laboral, a diferencia de un trabajador efectivamente empleado pero en condiciones precarias y con escasa capacidad de espera (Prieto, 1994). Desde un punto de vista similar,

${ }^{1}$ En 2008 el 31\% de los trabajadores estaban sobrecualificados, frente al 19\% de la media Europa-27 (Eurostat, 2011), es decir, la tercera parte de los trabajadores españoles lo hacen en un trabajo inferior al nivel académico que tienen.

${ }^{2}$ La economía sumergida se estima entre el 20-23\% del PIB de 1994 a 2006, ligeramente por debajo del 20\% en 2007 y 2008, Schneider (2010). 
desde la perspectiva económica se entiende que contar con bajos salarios no presupone la existencia de un "trabajador pobre" (Recio, 2006).

Por este motivo, se considera fundamental incorporar el contexto extra-laboral como una variable clave para entender la percepción de la crisis y las oportunidades de reinserción en el mercado de trabajo. No sólo por el efecto de las desigualdades sociales sobre las condiciones de empleo, sino también por la importancia que en la vivencia del desempleo tiene la existencia o no de cargas económicas (hipotecas) y de menores dependientes (Cantó, 2010). Existe una abundante literatura que contempla la influencia de estas variables en el mercado laboral y la pobreza, estudiando los "trabajadores pobres" (working poor), los "hogares pobres" o la "pobreza laboral" (Zalakin, 2006; Zubero, 2006; Recio, 2006; García Espejo et al., 2007; Arriba, 2008; Gutiérrez, 2009; Laparra, 2010; Cantó, 2010; Lopéz y Renes, 2011; Salido, 2012; Aragón, 2012; Belzunegui, 2012; Davia, 2013), que basan su análisis en estadísticas oficiales. Sin embargo, son todavía escasos los estudios que utilizan metodologías cualitativas (Erguía y Ortale, 2007; Vasilachis, 2003 o Malgesini, 2010), y menos los que contemplan la influencia de las variables extra-laborales en la percepción de la propia situación en el mercado laboral a partir de la crisis.

Este artículo - desde un enfoque cualitativo- pretende reconstruir las trayectorias laborales de los sujetos para averiguar el papel que la experiencia previa en el mercado tiene en la forma de percibir la crisis, de juzgar las oportunidades de trabajo y de desplegar una u otra estrategia para conseguir un empleo. Se plantea que el contexto en el que Castel identificó la "desestabilización de los estables" ha cambiado. Veinte años después, la desestabilización se ha generalizado, la inestabilidad se ha esparcido a buena parte de mercado laboral con el cambio a la norma flexible de empleo, como ocurre en el caso español y su "mercado dual imperfecto" (Prieto et al., 2009). Una nueva generación de población activa se ha incorporado al mercado, socializada en la incertidumbre laboral como norma. La crisis estaría provocando una nueva o segunda desestabilización cuyos efectos trataremos de analizar.

En primer lugar, se aborda brevemente la situación del mercado laboral en España, caracterizado por una creciente precariedad en el empleo. Ante esta situación, se presentan los postulados básicos de los discursos neoliberales basados en la idea de la empleabilidad y la activación, que guían gran parte de las políticas de empleo en Europa. A continuación, se pasa a identificar y profundizar en el análisis de las trayectorias laborales, así como en los significados y actitudes desplegados ante el mercado de trabajo, tratando de caracterizar aquellas trayectorias que, partiendo ya de situaciones de privación y vulnerabilidad, presentan una mayor probabilidad de experimentar procesos de mayor empobrecimiento. Finalmente, se recogen las respuestas o estrategias articuladas por el colectivo analizado para tratar de reincorporarse al mercado de trabajo y se presentan las principales conclusiones de este artículo. 


\section{El impacto de la crisis}

La crisis que está sufriendo España está alcanzando tales magnitudes que ni los peores pronósticos podían augurar su derrotero actual cuando comenzaron a caer los indicadores macroeconómicos a finales del año 2007. Las últimas cifras de la EPA, que muestran un incremento de la tasa de paro registrado hasta llegar al $26 \%$, suponen que uno de cada cuatro españoles y uno de cada dos jóvenes no tiene trabajo. El número de hogares con todos sus miembros en paro ya alcanza el $10,5 \%$ del total de hogares españoles ${ }^{3}$.

La precariedad en el empleo también se manifiesta en la tasa de temporalidad en nuestro país, que llega a situarse en 2012 en un $25 \%$, siendo la segunda tasa más alta de la EU-27, sólo superada por Polonia ${ }^{4}$, aunque alcanzó su pico más alto en 2006 (34\%). Esta tendencia decreciente de la tasa de temporalidad no ha redundado en una mejora de la calidad del empleo, al contrario, se explica por la creciente destrucción de puestos de trabajo. Por otro lado, el aumento del empleo a tiempo parcial, que en 2012 se sitúa en $15,3 \%^{5}$, también debe explicarse a la luz de la pérdida de trabajos a tiempo completo derivados de la crisis económica, sin perder de vista en ningún momento el carácter involuntario de este tipo de jornada de trabajo ni su marcado sesgo de género (Aragón et al., 2012a).

En estos años, los drásticos recortes en gasto social en favor del equilibrio del déficit, junto a las dos reformas laborales de septiembre de 2010 y febrero de 2012, han reducido considerablemente las indemnizaciones por despido, han debilitado la negociación colectiva y admitido nuevas razones para el despido procedente. Por el contrario, no han logrado parar la pérdida de puestos de trabajo, ni reducir las altas tasas de temporalidad y, en cambio, se ha acrecentado la indefensión de los trabajadores indefinidos.

Con la crisis económica y un modelo productivo asentado en la construcción y los servicios con mano de obra de baja cualificación, en la actualidad España cuenta

${ }^{3}$ Encuesta de Población Activa, $4^{\circ}$ trimestre 2012, (Instituto Nacional de Estadística). No hay grandes diferencias entre la tasa de paro masculina y la femenina, que se sitúan en el $25,6 \%$ y el 26,55\% respectivamente. En el caso de la Comunidad de Madrid, aunque el paro es más bajo que en el resto de España (20\%), en el último trimestre de 2012 Madrid es la región que registra un mayor descenso en los niveles de empleo. En todos los indicadores España supera en más del doble la media de UE 27: en 2011, la tasa de desempleo es del $21,7 \%$ y el $9,7 \%$, respectivamente para España y UE-27; la del desempleo juvenil es del $46,4 \%$ y $21,4 \%$, y la del paro de larga duración $9,0 \%$ y $4,1 \%$.

${ }^{4}$ La tasa de temporalidad de la media Europea-27 es del 14,1\%. Labor Force Survey, Eurostat, 2012.

${ }^{5}$ En el período $2007-2012$, se pasa de un $11,6 \%$ a un $15,3 \%$ de ocupados a tiempo parcial, mientras que los ocupados a tiempo completo descienden del 88,4\% al 84,7\%. En 2012, el $25,5 \%$ de mujeres tienen trabajos a tiempo parcial, frente a un solo $6,8 \%$ de hombres (EPA, IV trimestre). 
con el dudoso honor de encontrarse en el tercer puesto de la EU-27 en lo que se refiere al porcentaje de habitantes en riesgo de pobreza relativa, que a finales de 2011 llegaba al $27 \%$ de la población trabajadora y nada menos que al $26 \%$ de los menores de 16 años $^{6}$. Tener un trabajo ya no garantiza el mantenimiento de unas condiciones mínimas de bienestar, al contrario, cada vez se extiende más el fenómeno de los trabajadores pobres, que en el caso español están expuestos a remuneraciones y condiciones de empleo cada vez más precarias y a unos recursos sociales menguantes y de peor calidad propios de un Estado del Bienestar en profundo retroceso. Prueba de ello es la tendencia a la disminución de la renta disponible de las personas y de los hogares desde 2007, que algunos autores estiman en un 5\% hasta 2010 (Salido, 2012: 23), lo que ha llevado aparejada una importante disminución del consumo privado y, en algunos casos, la privación de bienes o servicios de primera necesidad y, en definitiva, a un creciente empobrecimiento de la sociedad española muy por encima de los países europeos (Fundación Foessa, 2013: 16).

Ahora bien, el crecimiento del trabajo precario y de las nuevas formas de pobreza en los países occidentales no surge de forma repentina por el estallido de la crisis; diversas dinámicas interrelacionadas producto de la competencia global, la desregulación de los mercados y los acelerados cambios tecnológicos facilitaron la financiarización de la economía que acabó deteriorando el tejido productivo. Aunque estos procesos globales tienen su peso, no constituyen una explicación suficiente; en todo caso, como señalan Miguélez y Prieto (2009), lo que cuenta prioritariamente es la fortaleza o debilidad del sistema de relaciones laborales que se establece en cada país y, en el caso de España, no puede soslayarse que la incorporación al empleo de jóvenes, mujeres e inmigrantes, contribuyó a engrosar las filas del empleo precario dado que en general se trata de grupos esencialmente frágiles y alejados de la influencia sindical. A estos contingentes hay que sumar el caso de los trabajadores industriales mayores que si consiguen volver al trabajo, posiblemente no será con las condiciones que tenían en sus antiguas empresas, ahora cerradas o deslocalizadas.

\section{El triunfo ideológico del neoliberalismo y la responsabilización del indivi- duo: empleabilidad y activación}

"No existe la sociedad, solamente los individuos y sus familias", Margaret Thatcher dictum en 1987, afirmación que sintetizó el rumbo del neoliberalismo para minimizar la protección social, los servicios públicos y acabar con lo que despectivamente llamó "The Nanny State". Las políticas neoliberales, basadas en la naturalización del mercado como agente distribuidor y la exaltación de la libertad del individuo para tomar decisiones racionales, derivó en cambios profundos en la filosofía de la

\footnotetext{
${ }^{6}$ Encuesta de Condiciones de Vida (Instituto Nacional de Estadística) y Eurostat.
} 
política social: los poderes públicos debían minimizar su intervención y los individuos debían asumir la responsabilidad de sus vidas y solucionar sus problemas sin vivir de los subsidios. Cabe decir que en esos años y por su trágica historia precedente, España estaba precisamente tratando de desarrollar el Estado del Bienestar con la extensión universal de la sanidad, la educación y la seguridad social, el aumento de las viviendas de protección oficial, y muchos otros esfuerzos en los que no nos podemos extender.

La Nueva Derecha y gran parte de la Socialdemocracia europea, especialmente la llamada Tercera Vía, han acercado posturas en la revisión del Estado del Bienestar, tanto en el énfasis sobre la responsabilidad individual como en la crítica a la "cultura de la dependencia". Pero más allá de las políticas sociales que fueron el primer objetivo, hoy la idea del compromiso individual, o la falta del mismo, se encuentran en la base de las explicaciones del endeudamiento ${ }^{7}$, el alivio de la pobreza $^{8}$ o la capacidad de conseguir y progresar en el empleo, temas que se condensan en los conceptos de empleabilidad y activación.

El término empleabilidad tiene un significado elusivo pero, tal como se usa en los organismos internacionales y en el mundo empresarial, alude a las habilidades, conocimientos y disposiciones psicológicas necesarias para conseguir y mantener un puesto de trabajo. Tal idea es muy próxima a la teoría del capital humano de los años sesenta, pero ahora se concibe como una ventaja competitiva que el individuo debe conquistar por sí mismo, independientemente de las condiciones sociales y económicas.

A pesar de su inconsistencia teórica, la consigna de la empleabilidad impregna las actuales políticas de formación y empleo sin tomar en consideración que en última instancia, ésta no depende primariamente de las capacidades de la persona sino del mercado de trabajo. Basta ver cómo buena parte de nuestra "generación mejor preparada" está hoy en el paro o malvive con un empleo precario.

Por otra parte, hay que considerar que la empleabilidad es una condición inestable y relativa, que no depende de su valor absoluto sino de cómo se posicionen otros en la competencia por un puesto de trabajo (Brown, P. et al., 2003 y 2011). Por último, al responsabilizar al individuo del desarrollo de las competencias y conocimientos necesarios para su empleabilidad, se hace caso omiso de las personas reales, de sus historias vitales indudablemente marcadas por la clase social, el

\footnotetext{
${ }^{7}$ Para un análisis del endeudamiento, ver Aragón et al.(2012)

${ }^{8}$ A pesar de la proliferación de programas contra la pobreza, pocos son los resultados positivos en tanto no están vinculados a estrategias de desarrollo sustentables a nivel nacional, regional y local. Como explica Molyneux (2006) gran parte de los programas están dirigidos a grupos específicos, mayoritariamente mujeres que deben responsabilizarse de determinados cometidos pero sin alterar sus roles tradicionales, más bien lo que acontece es que se re-tradicionalizan las divisiones de género.
} 
origen étnico, el género o el hábitat geográfico en que se desarrolló su experiencia familiar.

Estos cuestionamientos al concepto de empleabilidad, tal como se formula oficialmente, son pertinentes para entender las trayectorias y los proyectos de los "nuevos pobres". A pesar de su heterogeneidad, éstos no reproducen las características de la antigua pobreza urbana, como señala Wacquant (2008: 244 y ss.). En buena parte se trata de personas atrapadas por las tenazas de una marginación social y espacial de características masivas que van conformando un "precariado" naciente, sin representación política ni sindical. Ya no tienen identidad de clase porque han perdido los referentes laborales y comunitarios en medio de una crisis que los sobrepasa. En otros casos, las posibilidades de reincorporarse a la sociedad salarial son mayores porque han acumulado experiencias y conocimientos tácitos y, en el mejor de los casos, credenciales educativas, que los posiciona mejor en la dura competencia por el empleo. No obstante, difícilmente pueden considerarse empleables si no cambian las condiciones del mercado de trabajo, a pesar de las políticas de activación que la Unión Europea viene promoviendo desde los años noventa y que cobraron forma a partir de la Estrategia Europea de Empleo, aprobada en el Consejo Extraordinario de Lisboa en marzo de $2000^{9}$.

Diversos autores han señalado que aquella reunión marcó un hito en el tratamiento de la cuestión social, desde entonces centrada en el objetivo prioritario de la integración laboral. Para alcanzarlo, era menester reconfigurar los servicios de protección al desempleo (excepto para los colectivos muy vulnerables) y, al mismo tiempo, traspasar o diluir las responsabilidades del Estado en una estrategia con tres frentes: a) la activación de los individuos para la búsqueda de oportunidades de empleo y la actualización permanente de sus cualificaciones desarrollando la iniciativa, el dinamismo y la participación que requieren las nuevas formas de trabajo. Dicho en pocas palabras, activar la empleabilidad es casi convertirse en "empresario de uno mismo" como dice Foucault; b) la activación de la sociedad civil, en forma de partenariado entre diversos agentes implicados en un territorio, (especialmente las $\mathrm{ONG}$ ) para poner en marcha c) la activación de lo local (Martínez López, 2011) ${ }^{10}$.

Estas formas de activación podrían ser razonables si se planteasen de forma complementaria a la responsabilidad política del Estado en materia de empleo pero,

${ }^{9}$ La legislación española en materia de activación para el empleo se viene conformando de acuerdo con las directrices europeas. Véase la Ley 45/02, el Real Decreto-ley 3/2011y, lógicamente, el Real Decreto-ley 3/2012 de la nueva reforma laboral.

${ }^{10}$ Rodríguez Cabrero (2011: 16) señala que al igual que en otros países europeos los programas de inclusión activa adolecen de "falta de coordinación entre organizaciones públicas tanto a nivel horizontal como vertical, así como de la participación de la sociedad civil. Las asimetrías entre los diferentes tipos de renta mínima y su diferente relación con los programas de inclusión activa condicionan territorialmente la creación de círculos virtuosos entre renta, servicios y empleo o formación". 
ése no es el caso. Así formuladas dichas estrategias ponen en riesgo los derechos ciudadanos y el carácter universal de las políticas sociales, además de ser inviables socialmente para los sectores más vulnerables. Salvo que se trate de personas que cuentan con suficiente capital cultural, es difícil imaginar que quienes viven en la precariedad se dediquen a investigar cuáles son los yacimientos de empleo y gestionar su formación, ¿no será que el discurso de la empleabilidad está formulado desde la perspectiva de las clases medias? O ya en la tesitura más compleja de la sospecha foulcaultina ¿no cabría pensar que las exigencias de activar al parado no son sino dispositivos para deslegitimar su condición, disciplinarlo y, a efectos sociales, asegurar la gobernabilidad? (Ebersold, 2004; Borghi, 2011; Serrano et.al., 2012).

En esta dirección cabe señalar que la activación no es una mera apelación a la movilización del sujeto sino que se trata de una política que le impone condiciones muy duras, empezando por el hecho de que las prestaciones están condicionadas a su disponibilidad para aceptar una colocación, tenga ésta que ver o no con su formación y trayectoria. Se trata de una empleabilidad devaluada, subalterna respecto a las exigencias del mercado que Monereo (2003: 96-7) caracteriza como liberalizadora frente a una empleabilidad democrático social en la que, por el contrario, las políticas activas inciden en un trabajo acorde con la profesionalidad del desempleado y con los derechos sociales que consagran el acceso a un trabajo decente. Las presiones para que los desempleados encuentren trabajo en el menor tiempo posible se expresan también en otras disposiciones como la disminución de la cuantía y duración de la prestación, a las que se suma la coacción para aceptar los itinerarios de formación diseñados por los servicios de empleo, por cierto cada vez más configurados en la líneas neoliberales de la Nueva Gestión Pública (Weishaupt, 2010).

\section{La identificación de los perfiles de vulnerabilidad}

La mayor parte de los estudios sobre pobreza intentan identificar a los colectivos que se encuentran inmersos en procesos de creciente pauperización o en riesgo de exclusión social. Cabe citar por ejemplo el interesante análisis de la Cruz Roja en el Informe Anual sobre Vulnerabilidad Social 2008-2009, en el que se muestra que durante el primer año de la crisis se incrementó el porcentaje de los "nuevos vulnerables", que son aquellos que anteriormente estaban insertos en el mercado de trabajo, pero que al perder su empleo, empiezan a acumular factores de riesgo, empezando por el económico (Malgesini, 2010: 29). En el Informe Anual sobre Vulnerabilidad Social 2011-2012 se reitera la preponderancia del ámbito económico en cuanto a la situación de vulnerabilidad, especialmente en las personas que se encuentran desempleadas, "dibujando un mapa cada vez más homogéneo en lo que unos años antes presentaba mayor diversidad, ya que el riesgo de vulnerabilidad más alto estaba relacionado con otros factores como los problemas de salud, las adicciones, la desestructuración familiar, los malos tratos, etc." (Malgesini, 2013: 3).

Por su parte, el Informe de la Caixa, que analiza datos del Panel de Hogares de la Unión Europea (PHOGUE), a pesar de que insiste en la multidimensionalidad de 
la exclusión social, resalta la importancia de las variables de tipo laboral en la conformación de los colectivos más expuestos a los principales factores de exclusión social y de vulnerabilidad. Así, se identifican dos grupos principales: el grupo de excluidos del mercado laboral (en el que se incluyen fundamentalmente personas con baja formación -mayoritariamente mujeres- y que sufren pobreza severa, desempleados sin subsidios y jóvenes parados, así como enfermos y jubilados) y el grupo de inclusión social precaria que se configura fundamentalmente en torno a la experiencia laboral y el nivel formativo (Subirats et al., 2004: 121 y ss.).

En la misma línea, el estudio de la Red Europea de Lucha contra la Pobreza destaca cuatro grupos especialmente vulnerables ante las situaciones de aumento de las nuevas pobrezas: familias jóvenes con niños pequeños, parados procedentes de empleos de baja cualificación, mujeres con cargas familiares no compartidas (familias monoparentales), personas mayores con responsabilidades familiares que reaparecen (hijos en paro, avalando hipotecas, etc.), inmigrantes regulares en paro e inmigrantes en situación irregular (EAPN, 2009: 14-15).

Por último, en un reciente trabajo sobre la Socialización de la pobreza en Espa$\tilde{n} a$, se analiza la relación entre el género, la edad y la pobreza para identificar perfiles de mujeres pobres en España, y se destaca también que la vulnerabilidad laboral está en la base de lo que podemos llamar "las nuevas pobrezas, que en el caso de España son aquellas que afectan a jóvenes con formación media o superior, familias nucleares cuyos miembros principales están entre los 30 y los 49 años, y finalmente una parte de los inmigrantes" (Belzunegui, 2012: 26).

En el caso de la Comunidad de Madrid, según los datos de la Encuesta de Condiciones de Vida del 2010 -un año antes de iniciarse el trabajo de campo de esta investigación-, se estimaba que había alrededor de 1.400 .000 personas que se encontraban en riesgo de pobreza y exclusión, dato calculado a partir de la Tasa de Riesgo de Pobreza y Exclusión Social (Tasa AROPE), propuesta en el marco de la Estrategia Europa 2020, que se conforma a partir de la presencia de al menos uno de estos tres factores: a) que la renta se encuentre por debajo del umbral de pobreza, b) que se sufra alguna forma de privación material severa y que, en consonancia con lo anteriormente explicado, c) en el hogar se registre una baja intensidad de trabajo $^{11}$. De este modo, la Comunidad de Madrid presentaba una Tasa AROPE del 22\%,

${ }^{11}$ La estrategia Europa 2020 define la Tasa de Riesgo de Pobreza y Exclusión Social a partir de la presencia de al menos uno de estos tres componentes: el factor de umbral de pobreza constituido por el porcentaje de población que vive con una renta inferior al $60 \%$ de la renta mediana del país (antiguo y único indicador de riesgo de pobreza); la privación material severa, que ocurre en los hogares que no pueden permitirse 4 de los 9 siguientes ítems: pagar el alquiler o una letra, mantener la casa adecuadamente caliente, afrontar gastos imprevistos, una comida de carne, pollo o pescado al menos 3 veces por semanas, pagar unas vacaciones de al menos una semana al año, un coche, una lavadora, un televisor a color y un teléfono (fijo o móvil). Por último, se computa la intensidad de trabajo por hogar considerando el número de personas por hogar en edad de trabajar y el de las que efectiva- 
calculada con la mediana de renta regional y del $18 \%$ con la mediana de renta nacional, frente a la media para toda España del 25,5\%. Más de la mitad de esas personas, el $62 \%$, disponía de una renta inferior al $60 \%$ de la mediana autonómica (lo que equivalía a menos de $748 € /$ mes por persona adulta), pero no sufrían ni privación severa ni baja intensidad de empleo en sus hogares. El 11,5\% además de estar por debajo del umbral de pobreza, residían en hogares con baja intensidad de empleo y un porcentaje similar del $11,4 \%$ sufrían privación material severa, aunque no estaban por debajo del umbral de pobreza ni experimentaban baja intensidad de empleo ${ }^{12}$.

El análisis de las variaciones de la tasa AROPE según distintas variables sociodemográficas para el conjunto de la Comunidad de Madrid indica que esta tasa es mayor en mujeres que en hombres $(23,6 \%$ frente al $20,3 \%)$, más alta en los menores de 25 años $(23,5 \%)$ y en los mayores de 75 años $(26 \%)$ que en el resto de grupos de edad, así como en los que sólo tienen educación primaria (29,5\%). Lógicamente, la tasa de riesgo de pobreza y exclusión social es también más elevada entre los parados $(44,2 \%)$, los incapacitados para trabajar $(41,4 \%)$, los que se dedican a las labores del hogar $(32,2 \%)$ u otra clase de inactivos entre los que se encuentran los estudiantes $(45,4 \%)$, que entre los que trabajan a tiempo completo $(12,5 \%)$ o los que trabajan a tiempo parcial (28,2\%) (EAPN, 2011:16-19).

El presente artículo utiliza la información generada en el marco del proyecto $\mathrm{Mi}$ radas sobre la pobreza: representaciones sociales del sector de nuevos pobres de la Comunidad de Madrid en un contexto de crisis económica ${ }^{13}$. El trabajo de campo se enfrentaba a la dificultad de poder localizar a personas que estuvieran justamente sufriendo estos procesos de desestabilización y que por tanto se pudieran considerar nuevos pobres. Se realizaron seis grupos de discusión, dos grupos triangulares y ocho entrevistas abiertas, en las que participaron un total de sesenta personas ${ }^{14}$.

El universo de la investigación coincide en su mayor parte con los colectivos destacados en los estudios citados. Sin embargo, es preciso señalar que la selección de la muestra se ha llevado a cabo utilizando fundamentalmente dos criterios: por un lado, se primó la selección de personas con escasos recursos económicos que estuvieran en una situación de desempleo o realizando trabajos muy precarios, eventuales o a tiempo parcial (con salarios anuales por debajo del Mínimo Interpro-

mente trabajan, siendo una intensidad muy baja aquella que se encuentre por debajo del valor de 0.2 (EAPN, 2012: 2-3).

${ }^{12}$ Según la Encuesta de Condiciones de Vida del 2010, en Madrid el 13,6\% de la población vivía bajo el umbral de pobreza, el 4,5\% sufría privaciones materiales severas y el $4,5 \%$ vivía en hogares con baja intensidad de trabajo.

${ }^{13}$ Proyecto subvencionado por la Comunidad de Madrid y la UCM (convocatoria Dic. 2010) con número de referencia CCG10-UC/HUM-4984 y dirigido por Araceli Serrano.

${ }^{14}$ Para más detalles de los perfiles estudiados, remitimos al epígrafe de Objetivos y Metodología, así como al Anexo del artículo de Serrano, A.; Parajuá, D. y Zurdo, A.: Marcos interpretativos de lo social en la vivencia de la «nueva pobreza», en este número monográfico. 
fesional), ya que interesaba especialmente analizar a aquellos colectivos que, partiendo de una situación de cierta estabilidad, aún dentro de la precariedad, con el estallido de la crisis ven rápidamente cómo sus referentes se empiezan a destruir o transformar. Castel (1997) expresó hace años algunos de estos síntomas con el término de "desestabilización de los estables", es decir, la extensión de la precariedad e inestabilidad también al núcleo estable del mercado de trabajo. Por otro lado, los participantes seleccionados debían presentar alguno de los factores que incluye la Tasa de Riesgo de Pobreza y Exclusión Social (Tasa AROPE). De esta forma se asegura que la muestra de nuevos pobres no respondiera exclusivamente al nivel de renta, sino que se contemplaran otras dimensiones de la pobreza y de la exclusión, en línea con los nuevos presupuestos europeos.

El diseño de la muestra está vinculado por ello a lo que se puede considerar como procesos de heterogeneización de la pobreza, $\mathrm{y}$, por tanto, se ha recurrido a criterios de carácter socio-estructural para la selección de los participantes. Los criterios de las distintas posiciones consideradas han sido la clase social de partida -atendiendo también al origen social de los progenitores-, el nivel educativo, la posición previa y actual en el mercado de trabajo y en el proceso productivo, el género, la edad, el nivel de ingresos y de acceso a las prestaciones, el origen nacional, la situación en relación con la vivienda, así como la situación familiar. A pesar de toda esta diversidad, como se ha explicado, los participantes en el estudio comparten una característica común, que es la de encontrarse en una situación de gran precariedad, y en desempleo o subempleo en los últimos años.

El trabajo de campo se desarrolló en dos fases. En la primera, entre mayo y junio de 2011, se realizaron los grupos de discusión, en los que participaron personas con las siguientes características: jóvenes de ambos sexos, entre 22 y 30 años, de clase media baja y baja con estudios medios (GD1); varones de clase obrera sin cualificación, pero en posiciones previas de estabilidad o de "precaria estabilidad" (GD2); adultos de clase media baja, con edades intermedias (GD3); inmigrantes (GD4); mujeres en familias monoparentales (GD5); y jóvenes de clase obrera con baja cualificación que habían iniciado su proceso de emancipación (GD6). En la segunda fase de trabajo, entre junio y octubre de 2012, se realizaron los grupos triangulares y las entrevistas. En los grupos triangulares se incluyeron personas entre 35 y 45 años, con cualificaciones altas y trabajos precarios, sin cargas familiares y con participación en asociaciones o grupos socio-políticos (GT1); y profesionales en paro, con larga y relativamente estable trayectoria de trabajo profesional por cuenta ajena (GT2). Las entrevistas, por su parte, se realizaron a una mujer trabajadora pobre (E1); inmigrante marroquí (varón) (E2); inmigrante latina (mujer) (E3); varón de 50-60 años en paro con las prestaciones por desempleo agotadas (E4); varón de 60-65 años en paro con las prestaciones por desempleo agotadas (E5); trabajador pobre varón, joven (E6); trabajadora pobre mujer, joven (E7); y joven con estudios universitarios con trayectoria de inserción precaria en el mercado de trabajo (E8).

A partir del análisis de los discursos de los participantes, se han podido reconstruir las percepciones subjetivas y las vivencias de los sujetos, que como hemos señalado, dependen de su situación estructural, pero también de sus experiencias previas. 
Como hipótesis de partida, se propone que las consecuencias de la crisis habrán de ser distintas según se trate de colectivos estables o ya desestabilizados por la que podríamos llamar primera oleada de desestabilización, la analizada por Castel, y se entiende que ahora estos trabajadores están padeciendo una segunda desestabilización. Por otro lado, cabe suponer que también habrá de ser distinta la percepción de la crisis cuando ésta afecte a colectivos que sólo han conocido la inestabilidad, es decir, que su incorporación al mercado laboral ha sido más tardía que los anteriores y por tanto ya se han socializado en un mundo laboral cambiante, sin esperar fidelidad/continuidad en la empresa ni en la actividad desempeñada. Esto supondría aceptar que -en contra de lo que pudiera parecer- los sujetos aparentemente más vulnerables, social y económicamente, no sean los que se encuentran más desorientados para afrontar la crisis, y que por el contario los que hubieran vivido trayectorias más estables se encontrarán con más dificultades para salir de la situación actual e insertarse en un contexto laboral precario.

\section{Trayectorias laborales: entre la desestabilización y la inestabilidad}

El análisis de la percepción de cómo la crisis afecta a la situación de las personas en el mercado de trabajo parte, como se ha mencionado, de una perspectiva longitudinal que ha permitido identificar las principales trayectorias laborales. Se utiliza el término trayectoria laboral para indicar el período de tiempo y los sucesivos empleos por los que se ha ido pasando desde que se obtiene el primer empleo remunerado hasta el momento actual. En este artículo se opta por una conceptualización de la trayectoria que pone el énfasis en el registro del número de contratos, la rotación laboral y los cambios de la condición de la actividad (ocupación, desempleo, inactividad), cercano a los criterios de Mauro y Yañez, 2005 (op. cit. Miguelez et al., 2011) frente a otras aproximaciones más orientadas hacia la movilidad -ascendente o descendente- o la sucesión de posiciones ocupacionales y profesionales.

Aunque es bastante minoritario en la muestra, el trazado de esta trayectoria puede coincidir con el de una línea recta (empleo estable), pero no es habitual que siga una trayectoria ascendente, propia de los trabajadores ubicados en el segmento primario del mercado laboral (Piore y Doeringer, 1971; Piore, 1983). Más bien al contrario, para la mayoría de los entrevistados su incorporación al mercado laboral ha seguido un recorrido sinuoso, reflejando el cambio frecuente de un contrato a otro, dentro de la misma empresa o saltando entre distintas empresas. Tanto entre los que han seguido trayectorias lineales como los que han experimentado trayectorias sinuosas, se dan marcadas diferencias que obedecen a la distinta forma de incardinarse la trayectoria laboral con sus trayectorias vitales. A pesar de la diversidad de trayectorias laborales cabe señalar algunos rasgos comunes a todas ellas:

- Todos los participantes en este estudio cuentan con experiencia en el mercado laboral de varios años: desde los más jóvenes con cuatro o cin- 
co años de presencia en el mercado hasta los adultos que han perdido su empleo después de llevar al menos diez años trabajando.

- Igualmente, todos señalan la ruptura que se ha producido en su trayectoria en el mercado laboral como consecuencia de la crisis. Dicha ruptura se percibe traumática, por haberse producido de manera drástica e imprevisible para la mayoría de ellos.

- Refieren situaciones personales en las que el empleo estaba prácticamente garantizado, bien por continuar en la misma empresa o porque resultaba relativamente fácil cambiar de un empleo a otro.

- La llegada de la crisis ha supuesto un frenazo, un corte abrupto en su vida laboral. En estas circunstancias, consideran su situación crítica por la interferencia que dicha ruptura laboral supone en su trayectoria vital. Unas veces porque se truncan proyectos personales y/o familiares que iban a comenzar, otras porque trastocan la vida cotidiana tal y como estaba establecida hasta la irrupción de la crisis (vuelta al hogar familiar).

- Su relación con la crisis se va agudizando, precisamente por los efectos que la pérdida de empleo está teniendo sobre la convivencia, las relaciones sociales y su vida en general, haciendo que los efectos de la crisis se amplifiquen y vivan de manera más dramática según pasa el tiempo.

- La dimensión temporal de las trayectorias aparece claramente en la generalizada referencia a situaciones pasadas, más o menos alejadas en el tiempo, en todo caso anteriores a la crisis, para expresar la solvencia económica de la que gozaban, bien distinta a la situación de austeridad y carencia a las que tienen que enfrentarse ahora.

- Excepto entre los trabajadores más cualificados, todos los integrantes de las muestras consideran a los trabajadores inmigrantes como sus competidores, predomina el rechazo generalizado hacia ellos y abundan las manifestaciones que piden que se limite su participación en el mercado laboral en la actual situación de empleo.

Más allá de estos rasgos comunes, se identifican cuatro trayectorias laborales representativas de las distintas situaciones de empleo que caracterizan los procesos de la nueva desestabilización desencadenados a partir de la crisis. Estas trayectorias se diferencian según el perfil de los sujetos incluidos en cada una de ellas, sus experiencias y percepciones vinculadas al mercado laboral.

\subsection{Trayectoria de los trabajadores/as estables desestabilizados}

Se incluye en este primer grupo a aquellos trabajadores que su situación en el mercado laboral ha sido estable, o han conocido un periodo estable, hasta el estallido de la crisis. Son sujetos que han trabajado en la misma empresa durante muchos años seguidos, frecuentemente más de diez. Por regla general esta trayectoria implica recorridos de consolidación a medida que se acumula experiencia y se adquiere una cualificación validada con el paso del tiempo en la empresa. Esta experiencia y cualificación adquirida se incluye como capital que profundiza y afianza en la 
estabilización del trabajador en la empresa donde desarrolla su actividad. En un primer momento la situación de estabilidad adquirida les protegió de las consecuencias de la crisis, lo que expresan como "se oye la crisis" (GD2), ya que no se padece todavía en primera persona, siendo los trabajadores con contratos temporales los primeros afectados por los despidos. Estos trabajadores contaban con derechos laborales, estaban dados de alta en la Seguridad Social y gozaban de salarios bastante superiores al SMI (salario mínimo interprofesional), aunque parte del salario podía no estar recogido en la nómina, como suele ser habitual en el sector de la construcción.

Las personas que se incluyen en esta trayectoria suelen ser mayores de 40 años, contar con cargas familiares (hijos), están pagando una hipoteca y ser varones. La falta de formación reglada, en el caso de los trabajadores de la construcción o de los comerciales de la automoción, entre otros sectores afectados por la crisis se suple con el conocimiento que proporciona la pertenencia continuada a la misma empresa en la que se adquiere la cualificación necesaria para ser considerados trabajadores cualificados u obreros de oficio.

Por contar con una experiencia previa de estabilidad, la crisis les afecta especialmente debido a la falta de preparación o entrenamiento para afrontarla. Por un lado, la crisis ha minado su autoestima, pasando en un momento de ser válidos a no servir para nada, ya que se sienten incapaces de conseguir un empleo fuera de su campo de experiencia, empleos para los que además no se requiere ninguna cualificación (mozo de almacén, auxiliar de seguridad, limpieza, etc.). El capital acumulado en forma de experiencia se convierte en un desecho, sin valor alguno:

"Trece, trece años en la misma empresa, de calefactor e instalador de gas, se supone que es porque vales" (...) no vales para nada, porque si echas para mozo, para repartir propaganda, echas para..., y no llaman de ningún lado ... no valgo para nada...” (...) Y entonces ¿Dónde queda la experiencia y toda la... mierda que tenemos?" (GD2).

Por otro lado, tampoco están preparados para afrontar la crisis porque no han tenido tiempo de experimentar la transición de una situación a otra, se sentían seguros en sus trabajos y habían organizado sus vidas contando con esa estabilidad (consumo, familia, viajes...). En la nueva y repentina situación carecen de suficientes redes sociales ya que sus compañeros han sido también despedidos. Lo que les lleva a vivir de forma muy angustiosa el desempleo "te quedas en la calle de un día para otro", a rebajar muchísimo sus expectativas en el día a día, conformándose con tener una "oportunidad", una "llamada" que nunca llega. Hasta el punto de calificar su situación como "agónica", cualquier trabajo por corto que sea se convierte en tiempo que va sumando para estirar todo lo posible la prestación por desempleo:

"Porque esos tres meses es lo que alargo luego el paro, o sea, se trata de alargar la agonía [La agonía, la agonía de todos], alargarla un poco" (GD2). 


\subsection{Trayectoria de los trabajadores/as inestables desestabilizados}

Se sitúan aquí las personas que han tenido trabajos "precarios", encadenando contratos temporales o por obra y servicio en varias empresas, o en la misma, con alta movilidad laboral. Este sería el caso fundamentalmente de los trabajadores de la construcción que vivieron un buen momento económico:

"-Pues yo en diecisiete años nunca he estado indefinido, nunca, nunca, en diecisiete años nunca he estado indefinido, siempre... un año, te finiquito, otro año, te finiquito, otro año te finiquito, otro año te finiquito, seis meses, tres meses..." (...)

-¡Ah! pero, bueno, podías ir a un sitio, podías ir a otro, había movimiento..." (GD2).

Son trabajadores que tiene escasa o ninguna cualificación y que aprovechando la bonanza económica han podido mantener cierta sensación de estabilidad hasta que llegó la crisis. Cuenta con una amplia trayectoria en el mercado laboral, que ellos califican como "experiencia", pero por tratarse de trabajos apenas cualificados, ligados a prácticas rutinarias o de escaso contenido no suelen ser valorados por los potenciales empleadores. Al tener además cierta edad, mayores de 35 años, la crisis ha coincidido con un momento vital en el que en general ya habían iniciado la formación de una familia. Cuentan por tanto con cargas familiares, hipotecas y suelen ser mayoritariamente varones. Se diferencian de la trayectoria 1 por la falta de oficio: se trata de un colectivo sin profesión, al haber desempeñado trabajos diversos en distintas empresas. Han tenido acceso, como los anteriores, al consumo generalizado, gracias a sueldos bastantes más elevados que los actuales y por el acceso fácil al crédito, impulsado, como ellos reconocen, por los bancos.

Debido a la relativa facilidad para encontrar trabajo antes de la crisis, la percepción que estos trabajadores tienen de su trayectoria laboral muestra la normalidad y tranquilidad con la que afrontaban la incertidumbre generada por el continuo trasiego entre empresas. Las expresiones positivas utilizadas para referir aquellos años tales como "había movimiento", "podias elegir" GD2, contrasta con la angustia y desesperación vividas actualmente. A la falta de empleo actual se une la escasa cuantía de las prestaciones por desempleo, y la inexistencia o mínimas indemnizaciones debido a la frecuente irregularidad contractual de los trabajadores inestables. Sin embargo, cuentan con redes personales más amplias que los trabajadores estables (cuya trayectoria laboral sólo les ha permitido relacionarse con personas de su empresa o sector), precisamente por su constante deambular. Esto supondrá que son numerosos los contactos y por tanto mayores las oportunidades de conseguir pequeñas "chapucillas" para ir tirando.

\subsection{Trayectoria de los trabajadores/as inestables estructurales}

En este grupo se encuentran aquellas personas que no llevan tanto tiempo en el mercado laboral, a diferencia de las dos trayectorias mencionadas con anterioridad. Pueden ser los más jóvenes, pero también se incluye a personas de más edad como los inmigrantes y mujeres sin cualificación. En general el nivel de cualificación de 
estos trabajadores es muy bajo o inexistente. Proceden mayoritariamente del sector servicios con empleos de auxiliar de vigilante, limpieza, peluquería, etc. A diferencia de los inestables desestabilizados, se han incorporado al mercado de trabajo en la fase final del periodo de bonanza, están en el tramo inicial de su carrera laboral, en un periodo de escasez de empleos en el que ya no es fácil cambiar de puesto de trabajo. Es el caso de los jóvenes sin estudios, que están dispuestos a incorporarse a cualquier sector del mercado laboral al no contar con experiencia suficiente en ningún ámbito, lo que presupone una desorientación, una falta de profesión que ellos mismos detectan: "Si no tienes una profesión, ... más o menos, pues eso, hecha, ya tuya, si no nada" (GD6). Pero como contrapartida, tienen una mayor capacidad de adaptación, están abiertos a cualquier tipo de trabajo con un mínimo de condiciones, aunque ahora "como mucho hay trabajillos" (GD1), no son realmente trabajos.

No tienen la misma urgencia que los trabajadores de más edad en encontrar un empleo, ya que su situación es reversible al no haber tomado todavía decisiones vitales importantes. Viven en casa de sus padres o de alquiler pero pueden volver a casa de los padres, y tampoco tienen hijos. En este grupo la adquisición de vivienda se ha sustituido en algunos casos por el coche. Aun así han tenido que modificar y recortar sus gastos de ocio (beber en casa, pasear en lugar de consumir en los bares), y suelen contribuir a los gastos del hogar familiar por las dificultades económicas que tienen sus progenitores, que en algunos casos están también afectados por el desempleo o/y por vivir separados. Su situación actual contrasta con el consumo desmedido que reconocen sin pudor en el pasado, declarándose casi engañados, "estafados" por haber sido incitados al consumo: "las tarjetas de crédito... es vamos la peor estafa":

"Nos han vendido un poco: el vivir un poco por encima de nuestras posibilidades, yo sin ir más lejos llegué a pedir un crédito en el banco de cuatro mil euros que me fundí en: en una semana, o sea me lo fundí en caprichos, (...) te, te enseñan a... a... o te quieren hacer ver que teniendo más dinero o teniendo según qué aparato eres mejor, eres más chuli" (GD6).

Al tener una posibilidad de aguante mucho mayor ("Yo, gracias a Dios, la crisis no la he sentido del todo" GD6) no están dispuestos a asumir cualquier empleo como hacen los que tienen cargas familiares o hipotecas "Pero es que hay gente que está hasta aquí arriba y lo cogen, de eso se aprovechan". Su actitud es más la de esperar hasta que acabe la crisis, y aprovechar mientras tanto el tiempo para formarse. Pero, como veremos más adelante en relación a las estrategias, se trata de una formación centrada en la acreditación compulsiva.

La situación vital de los inmigrantes -ocupados en puestos de trabajos que no requieren cualificación- y de las mujeres descualificadas, explica que no cuenten con tiempos de espera. Su situación de urgencia pudiera acercarles al grupo de trabajadores de la trayectoria 2. Sin embargo, se diferencian de éstos, y se inscriben defini- 
tivamente en la trayectoria de los jóvenes, por la versatilidad y disponibilidad para amoldarse a cualquier sector del mercado laboral.

\subsection{Trayectoria de los trabajadores/as inestables coyunturales}

Esta trayectoria se define en su conjunto por una incorporación al mercado laboral incompleta o circunstancial, en la que cabe diferenciar una doble línea o recorrido: la Línea 1, que incluye personas cualificadas, cercanas a los 40 años, con estudios superiores o de grado medio, que han ingresado en el mercado de trabajo con empleos que no corresponden a las expectativas que tenían acorde con su formación, o no les satisfacen totalmente. Se incorporaron al mercado de trabajo, pero se encuentran atrapados en una situación que en la actual coyuntura económica no les permite continuar su trayectoria laboral.

Característico de los inestables coyunturales de la Línea 1, es la ausencia de hijos o de cargas familiares. Pueden tener hipoteca que suscribieron en solitario, tuvieran o no pareja estable. En la actualidad, la confianza inicial en sus capacidades y posibilidades empieza a debilitarse porque afrontan el presente sin ingresos, gráficamente lo expresan diciendo que "poco a poco la situación aprieta" (GT2). Critican el abuso de las nuevas condiciones laborales impuestas con la crisis, hablan de "explotación", de "condiciones de mierda", y denuncian la mentira sobre las oportunidades existentes en otros países para animarles a emigrar. Sin embargo, no descartan salir al extranjero, aunque a disgusto, porque saben que las cosas son más difíciles de lo que se transmite en los medios de comunicación y porque prefieren la calidad de vida de España.

Las personas situadas en la Línea 2 parten con menor nivel de cualificación y son más jóvenes que los de la Línea 1. Esta circunstancia hace que en ellos pese más su situación vital que la situación que tienen en el mercado laboral. Se han incorporado recientemente al mercado laboral; pueden ser becarios, estudiantes que trabajan, o bien personas que no tienen interés en incorporarse plenamente en él. Hacen de ello una forma de vida, aceptando trabajos esporádicos, poco remunerados, junto con otras actividades propias de la juventud y de su situación más despreocupada y sin cargas. En muchos casos esta situación coyuntural puede pasar a ser estructural, por ejemplo cuando los estudios no culminan con éxito. De esta forma, lo que antes era una elección se convierte en una necesidad y se ven obligados a aceptar trabajos descualificados pero en situaciones más adversas. Parte de estos sujetos pueden acabar perteneciendo al grupo de la trayectoria 3 (inestables estructurales).

\section{Significados y actitudes ante la crisis y el mercado laboral. Tendencias hacia un mayor empobrecimiento}

Teniendo en cuenta las distintas trayectorias laborales identificadas, se observa que el significado atribuido a la crisis y su efecto sobre el empleo depende de la posición estructural del sujeto en el mercado, que varía en función de la existencia 
de cualificación formal, experiencia profesional u oficio o, por el contrario, de la total ausencia de estas características. Estos significados se relacionan con el mayor o menor efecto transformador del mercado laboral que los entrevistados otorgan a la crisis. Cuando a la crisis se le atribuye un papel transformador los cambios resultantes se consideran radicales, por el contrario, si los cambios se consideran menores el papel atribuido a la crisis es más el de reformar o retocar el mercado.

\section{Figura 1.- Significados y actitudes ante el mercado laboral según las distintas trayectorias identificadas}

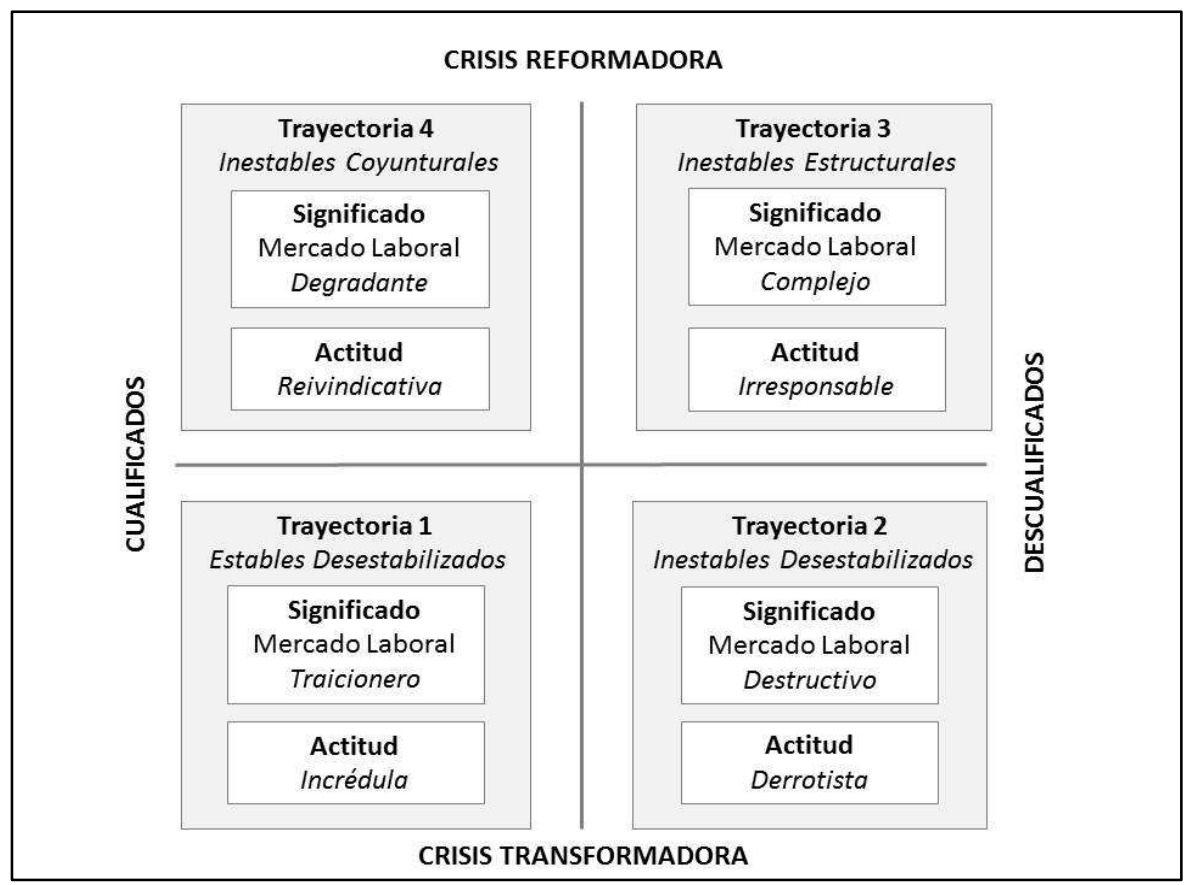

En la figura anterior se presentan las trayectorias explicadas y los significados atribuidos al mercado de trabajo en relación a los niveles de cualificación y a la percepción de la crisis actual. Así, puede observarse que aquellos que se encuentran inmersos en la trayectoria 1 (estables desestabilizados), dan mayor importancia o ponen en valor las capacidades con las que cuentan, pero sin embargo ya no son valoradas en un mercado laboral que consideran no volverá a ser el mismo. Se sienten engañados o traicionados al observar como su experiencia se convierte en algo residual, sin valor. El mercado laboral se entiende traicionero, toma el significado de falsedad. Por el contrario, en la trayectoria 2, los inestables desestabilizados están desbordados por la nueva situación y se sienten incapaces de encontrar una salida ya que no cuentan ni siquiera con un oficio o habilidades para adaptarse a 
la crisis. Para ellos el mercado laboral es destructivo, de hecho físicamente se sienten literalmente acabados (muchos de ellos padecen depresión).

En el eje horizontal superior, en la trayectoria 3 de los inestables estructurales el mercado laboral resulta incompresible por su gran complejidad. Por un lado, porque desde la óptica de los sujetos, no cuentan con la preparación ni la información necesaria para poder reorientar su incorporación laboral. Por otro, porque al hacerse más complejo, el mercado exige más habilidades. Al no contar con ellas, aumenta su inseguridad, el temor al fracaso resulta paralizante y prefieren esperar. Dicha espera está justificada porque aunque la crisis ha tenido un efecto "reformador" del mercado laboral, éste será pasajero. Es decir, se trata simplemente de un cambio de ciclo, en sus palabras: "una mala época", pero pasará. Confían en que de estar necesitados algún "trabajillo" obtendrán. Después de todo, ellos ya han conocido la inestabilidad, la crisis tan sólo la generaliza y profundiza; es más de lo mismo. Los inmigrantes -por venir de un contexto distinto y más desfavorable- viven esta complejidad además con incredulidad, ya que ni la crisis ni la pobreza les parecen reales comparadas con las de su país de origen. Por el contrario, en el caso de las mujeres con baja cualificación -por su desvinculación anterior del mercado laborallo viven con mayor dramatismo y stress al tener cargas familiares.

Continuando en el eje superior, los sujetos que han desarrollado la trayectoria 4 de los inestables coyunturales comparten la concepción pasajera de la crisis. Si los anteriores se sienten víctimas de la sociedad de consumo que les ha orientado hacia el gasto desmedido, éstos lo están por el trato degradante que el mercado les depara después de años de esfuerzo y trabajo.

Por otro lado, cada uno de los significados atribuidos al mercado laboral se corresponde con una actitud determinada por parte de los integrantes de cada una de las trayectorias descritas (Figura 1). En la trayectoria 1, ante la falsedad del mercado laboral, se mantiene una actitud de incredulidad o desconfianza, de asombro o shock por la situación que viven, de recelo e inseguridad por los cambios tan rápidos e inesperados que están afrontando en su vida laboral. En la trayectoria 2 la actitud es más bien derrotista, con falta de fuerzas para enfrentar la búsqueda de empleo en un mercado que se está desmoronando sobre ellos. En la trayectoria 3, la irresponsabilidad define la actitud de quienes no se sienten culpables de los excesos consumistas ni de haberse incorporado prematuramente al mercado, pasando la responsabilidad de sus decisiones a la sociedad por no haberles sabido advertir de los riesgos y consecuencias de sus acciones. Mujeres e inmigrantes se sienten igualmente irresponsables de la crisis, aunque por motivos opuestos a los jóvenes. No han consumido ni derrochado en exceso, la situación de crisis le ha venido sobrevenida, impuesta. Por último, en la trayectoria 4 predomina una actitud reivindicativa de la posición que consideran les pertenece en la sociedad por méritos propios.

De los significados y actitudes atribuidos por los sujetos que componen cada trayectoria se puede concluir que el riesgo de un mayor empobrecimiento asociado al mercado de trabajo (Figura 2) cuenta con unos criterios objetivos como son: la situación de desempleo, los efectos psicológicos que éste produce en los propios 
sujetos y la existencia de cargas familiares ${ }^{15}$. Aquellos colectivos que han evidenciado mayores niveles de culpabilidad, son más depresivos porque perciben que el mercado de trabajo no cuenta con ellos, y que por tanto, las posibilidades de encontrar un empleo son escasas o ninguna, son los que más posibilidades tienen de convertirse en parados de larga duración haciendo que la situación de desempleo se convierta en endémica. La escasa cualificación y la existencia de cargas familiares devienen insostenibles, al no disponer de ingresos suficientes para continuar cumpliendo con las obligaciones contraídas, lo que contribuye a mermar todavía más su autoestima.

${ }^{15}$ Son muchos los estudios que analizan los efectos psicosociales del desempleo. Sin duda el clásico, y de renovada actualidad, continua siendo la investigación de los años treinta Los parados de Marienthal, de Lazarsfeld (1996). 
Figura 2.- Trayectorias laborales y tendencias hacia un mayor empobrecimiento

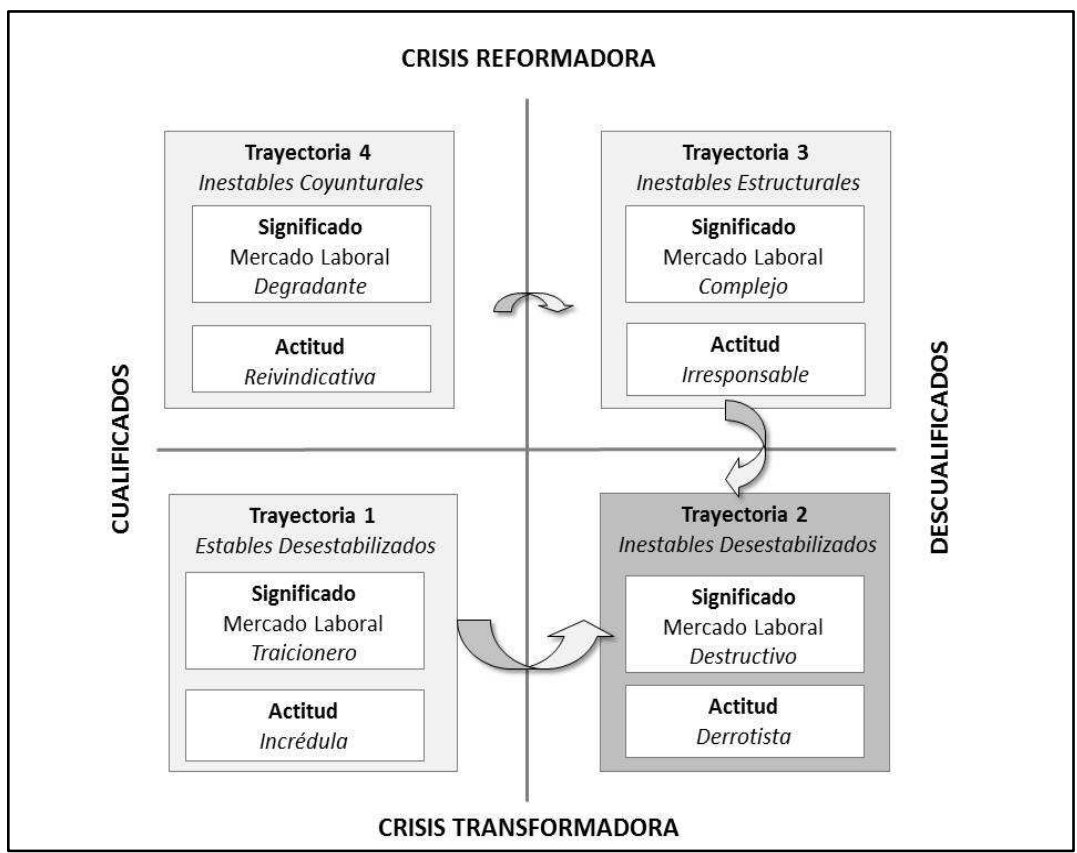

Fuente: Elaboración propia.

Nota: Las flechas indican la tendencia del desplazamiento y el tamaño de éstas el volumen de sujetos implicados y el mayor o menor potencial de cambio de una trayectoria a otra.

Teniendo en cuenta estos criterios y apreciaciones se identifican los grupos sociales inscritos en las trayectorias 1, 2 y 3 como aquellos con mayor posibilidad de sufrir un agravamiento de la situación de pobreza; situación que eventualmente podría asimilarse a la de aquellos que experimentan de forma simultánea los tres factores que contempla la Tasa Arope anteriormente descrita ${ }^{16}$ de pobreza. Es posible a su vez ordenar estas trayectorias de mayor a menor riesgo. Especialmente vulnerable es la situación de los inestables desestabilizados (trayectoria 2) precisamente por el agravante que supone su fragilidad emocional y la existencia de cargas

${ }^{16}$ En el caso de la Comunidad de Madrid, se estimaba que un 2,3\% del total de la población (lo que equivalía a unas 30.000 personas), se encontraba en este grupo de riesgo de pobreza y exclusión, entre los que destacaban el $27 \%$ de los hogares monoparentales, el $47 \%$ de las personas con educación secundaria de $1^{\mathrm{a}}$ etapa o menor nivel educativo, el $85 \%$ de los parados y el 38\% de los extracomunitarios (EAPN, 2011:28 y ss.). 
familiares, pero en esta trayectoria también podrían acabar, en primer lugar, los trabajadores de la trayectoria 1, abruptamente sacados del mercado, poco habituados a vivir en la incertidumbre, pero algo más protegidos que los anteriores al contar con cierto colchón de ahorro ( $\mathrm{y}$ en algunos casos patrimonio). Estos trabajadores (trayectoria 1) están menos adaptados que los que se integran en la trayectoria 3 , que al haber transcurrido la mayor parte de su vida laboral en mercados fuertemente precarizados afrontan la inestabilidad con mayor naturalidad, y por tanto con un coste psicológico menor. Sin embargo, parte de éstos, pueden pasar también a la trayectoria 2 empujados por su trayectoria de vida, ya que con la edad aumenta la necesidad de contar con ingresos regulares. Mejor situados están los grupos sociales de la trayectoria 4 , a los que cabe atribuir más fortaleza psicológica y recursos personales derivados de su cualificación o juventud.

\section{Estrategias de inserción en el mercado laboral}

Una vez descritas las principales trayectorias laborales identificadas pasamos a examinar algunas opciones que los sujetos encuentran en el mercado de trabajo para acceder a un nuevo empleo y, en última instancia, para sobrevivir. Para ello analizamos las estrategias que despliegan en la búsqueda de empleo y en la inserción en el mercado de trabajo.

En general, los sujetos analizados coinciden en que la búsqueda de trabajo supone una inversión de tiempo y energía, pero también económica, en cuanto al gasto que implica la realización de fotocopias, el transporte, las llamadas de teléfono, y en algunos casos, desplazarse de ciudad. También se alude al cambio que ha tenido lugar en cuanto a los procedimientos de búsqueda y de selección de los trabajadores. La búsqueda directa y presencial que implica "patearse la calle" para entregar personalmente el currículum en los centros de trabajo ("la obra", el comercio, el restaurante o el almacén, por ejemplo), ha dejado de ser eficaz ante el constante flujo de demandantes. En su lugar se opta por los anuncios que se publican en periódicos y en los portales de empleo a través de internet. Pero en ambos procedimientos se destaca la existencia de ofertas de trabajo sin contrato, con salarios por debajo del salario mínimo interprofesional, e incluso de puestos de trabajo que no existen ${ }^{17}$ y que son utilizados para obtener información de los solicitantes con fines publicitarios.

En este contexto se han identificado tres estrategias principales que aparecen en el proceso de acceso a un nuevo empleo: disponibilidad/versatilidad, inversión en formación y autoempleo. Por estrategia de disponibilidad/versatilidad hacemos referencia a la predisposición y a las posibilidades que tienen los sujetos de realizar

${ }^{17}$ El País, 11-1-2013, “Ofertas sorprendentes":

http://economia.elpais.com/economia/2013/01/11/actualidad/1357933025_975462.html. 
diferentes trabajos con condiciones laborales distintas a las que tenían antes de la crisis. Por otro lado, y en función de la creciente demanda de personal cualificado, en muchos casos se decide invertir en educación, aún contando con estudios superiores. Y, en última instancia, se opta por el autoempleo, como única solución para volver al mercado laboral. Pasamos a describir cada una de estas estrategias teniendo en cuenta la cualificación y el nivel educativo de los grupos que se incluyen en las trayectorias definidas previamente.

En lo referente a la disponibilidad/versatilidad, encontramos que los trabajadores más disponibles son los mayores de 40 años con cargas familiares. Los "obreros de oficio" y trabajadores cualificados (trayectoria 1) que durante muchos meses han intentado hacer valer su experiencia, con la esperanza de que alguna empresa confiara otra vez en ellos, hacen referencia a que en el momento actual buscan ya "cualquier cosa", es decir, trabajos precarizados con bajos salarios que incluso ni siquiera están disponibles, porque "ahora ya ni eso, ni eso; no hay trabajo de $600 €$ al mes" (GD3). Estos trabajadores, junto con los "precarios", vinculados principalmente al sector de la construcción (trayectoria 2), son los que perciben más complicada su reubicación en el mercado de trabajo, por lo que optan a trabajos con peores condiciones labores a las que tenían anteriormente, y en última instancia a la realización de "chapuzas", a las que acceden a través de las redes de contactos que tienen desde hace años en el barrio, el entorno familiar, y "amigos que intentan ayudar" (GD2). Pero frente a la mayor disponibilidad que muestran en este momento, son menos versátiles que otros grupos por haber desarrollado su trayectoria laboral durante muchos años en sectores de actividad muy específicos. Las mujeres con hijos a su cargo (trayectoria 3), muchas de las cuales dejaron de trabajar cuando éstos nacieron y se han incorporado al mercado laboral tras la separación, muestran un alto grado de versatilidad en relación al desempeño de diferentes puestos de trabajo relacionados con los sectores en los que aún existen ofertas, (servicio doméstico, limpieza u hostelería), pero tienen menor disponibilidad al ser también empleos precarios con horarios y condiciones que no les permiten compatibilizar el trabajo con el cuidado de los hijos.

De esta forma, unos y otros se ven abocados a la realización de trabajos sin derechos laborales y sin estabilidad. Situaciones que someten a los sujetos a la contradicción entre aceptar trabajar sin contrato cobrando "en negro", y por tanto estar disponibles por la urgencia del presente, o esperar otro trabajo que puede que no se encuentre.

“-Es lo peor, pero si es lo que hay

-Ya, pero: no tienes derecho a nada, si te pones mala nada (...) yo lo odio, quiero estar cotizando, quiero hacer mi declaración (...): O sea en negro, pues eso, es la solución para comer algo, punto, ya está" (GD5).

Los jóvenes sin cualificación y de nivel cultural bajo (trayectoria 3), -muchos de los cuales han vuelto al hogar familiar-, muestran menor disponibilidad que los grupos anteriores para realizar otros trabajos, aunque son más versátiles para adap- 
tarse e integrarse a diferentes sectores de actividad, en parte por su edad, y en parte por carecer de profesión. Por otro lado, los que menos disponibilidad muestran de todos los grupos analizados son los jóvenes y los trabajadores/as que cuentan con un nivel de formación alto (trayectoria 4), ya que buscan empleos más relacionados con su área de especialización. Son los únicos que reconocen que renuncian a ofertas alejadas de sus expectativas. En algunos casos, en función del nivel formativo que tienen, también han reorientado sus conocimientos a otros ámbitos laborales (como la enseñanza), lo que les permiten seguir realizando trabajos acordes con su nivel de cualificación. Por ello, aunque muestran menor disponibilidad, cuentan con una mayor versatilidad para adaptarse a otros nichos de empleo.

"Cada vez vas bajando más el listón está claro, y yo lo veo bajando, día a día lo veo bajando, en fin, tienes que vivir y tienes que entonces no sé, ya veremos, yo sigo con esperanzas de encontrar trabajo de lo mío y, pero si me tengo que poner a trabajar, pues en lo que sea lo haré pero a ver, bueno (GT2).

La segunda estrategia, la inversión en formación, consecuente con el discurso de la empleabilidad, predomina entre los más jóvenes con un nivel de cualificación bajo (trayectoria 3), tratándose de una formación vinculada fundamentalmente con la formación ocupacional a partir de cursos en el INEM. En este grupo, la formación se entiende más como acreditación, es decir, se trata de conseguir carnets, documentos que certifiquen sus capacidades o les permitan demostrar que las han ampliado. No pretenden profundizar o ampliar conocimientos previos en un campo específico, ni se orientan a la formación reglada. Por el contrario, son abundantes las referencias a la realización de cursos de manera acumulativa, casi compulsiva: "me he sacado todos los carnés en el INEM y tal, me he sacado un curso ahora por la UGT de técnico sanitario" (GD6) o a aprovechar para sacar el título de graduado, o alguna otra titulación básica con la que tratar de paliar su falta de experiencia y de formación mientras dura la crisis.

"yo creo que en la crisis el que no tenga trabajo no hay que dormirse, [hay que] formarse y así cuando acabe la crisis... poder elegir. Yo creo que nos ha pillado una mala época, tenemos un edad que deberíamos estar trabajando, acumular experiencia, una antigüedad en una empresa y empezar a ahorrar, comprarte tus cositas, tu coche" (GD6).

En una situación similar de inversión en formación se encuentran los trabajadores que tienen estudios superiores (trayectoria 4). Entienden que aunque están atravesando un momento difícil, la mejor forma de estar preparados para el futuro es seguir formándose. A pesar de reconocer que los títulos que tienen no les han facilitado la inserción en el mercado laboral, ni en su área de experiencia ni en las condiciones laborales que esperaban, no descartan realizar algún máster u otra especialización.

Sin embargo, entre los trabajadores que tienen más de 30-35 años de las trayectorias 1,2 y 3 , no se concibe la estrategia de formarse para nuevos puestos de 
trabajo. El nivel de estudios máximo que tienen es el graduado escolar o formación profesional de primer grado, y no se sienten preparados para adquirir nuevos conocimientos. Así lo explicitan cuando alguno de ellos ha optado por este itinerario realizando un curso en el INEM: "me está costando mucho porque no he tocado un libro en mi vida" (GD2).

En lo referente a la tercera estrategia de autoempleo se observa que, ante la falta de opciones laborales, en algunos casos se contempla la posibilidad de que sean los propios sujetos los proveedores del trabajo. Por ejemplo, entre los trabajadores cualificados de la trayectoria 1 se encuentran aquellos que han asumido perfectamente el discurso de la activación, y que tras muchos meses de paro y tener una edad que ronda los cincuenta años han optado por utilizar parte de su patrimonio para "comprar" un trabajo (en este caso para adquirir una licencia de taxi).

"Eso en casa es lo que hemos tenido que hacer, porque me quedé yo sin trabajo, después mi marido (...) tenerte que hipotecar tu casa, cosa que no estaba hipotecada, que yo la tenía pagada, hipotecar mi casa para que mi marido pudiera tener trabajo" (GD3).

Los jóvenes de la trayectoria 3 también hacen referencia a los puestos de trabajo como comerciales que les ofrecen en los que la empresa "se lava las manos" (GD1), siendo ellos los que deben asumir los gastos y los riesgos. Perciben que frente al trabajo discontinuo, a los contratos por obra y servicio, a los "trabajillos" o las llamadas "chapuzas" que realizan en ocasiones a cambio de unos escasos ingresos, el denominado autoempleo les niega no solo garantías laborales, sino incluso un salario mínimo que se ve en peligro en el supuesto de que no logren realizar ninguna venta. Aunque con carácter minoritario, entre los trabajadores con estudios superiores (trayectoria 4) es donde se plantea de forma más precisa la posibilidad de crear una empresa entre amigos o compañeros de otro trabajo para encontrar un hueco en el mercado, aludiendo al hecho de que el contexto actual es necesario ser emprendedor: "Yo creo que hay que inventarse cosas" (GT2).

Como hemos expuesto, en las tres estrategias analizadas los sujetos reproducen el discurso de la empleabilidad puesto que asumen la responsabilidad de su propia inclusión laboral y social en cuanto a la necesidad de ser versátiles y estar disponibles, tener formación o ser emprendedores. Asimismo, se observa que las estrategias descritas conducen, en el mejor de los casos, a oportunidades de empleo que no dejan de estar vinculadas con la precariedad y la inestabilidad.

\section{Síntesis y conclusiones}

La crisis que comenzó en 2008 ha generado un proceso creciente de inestabilidad y precariedad laboral, desempleo y vulnerabilidad social que está deteriorando cada vez más el mercado de trabajo. Esta situación ha incidido no sólo sobre los colectivos que ya se encontraban en una situación de previa desestabilización, y que 
ahora estarían sufriendo lo que hemos denominado como segunda desestabilización, sino también sobre buena parte del núcleo estable del mercado laboral. Todos ellos pasarían a padecer situaciones que podemos denominar de nueva pobreza.

Este trabajo partía de la idea de que las consecuencias de la crisis son diferentes para los distintos grupos o perfiles, en función del grado de estabilidad o inestabilidad que han tenido en el pasado. De las cuatro trayectorias descritas, la de los trabajadores estables desestabilizados, afecta fundamentalmente a aquellos sujetos que han desempeñado su empleo de forma estable durante la mayor parte de su vida laboral en el mismo sector de actividad y en pocas empresas, en las que han adquirido cierto grado de cualificación. En la segunda trayectoria, la de los trabajadores inestables desestabilizados, se incluyen los que han desarrollado su vida laboral realizando diferentes trabajos, con contratos temporales, y muy ligados al sector de la construcción. Para los sujetos incluidos en estas dos trayectorias, principalmente mayores de 40 años con cargas familiares y bajo nivel educativo, la crisis tiene un efecto transformador que da cuenta del agotamiento de un modelo según el cual los trabajadores accedían a los puestos de trabajo en función de la experiencia acumulada durante años y podían mantener económicamente a la unidad familiar, y en ocasiones acceder a un nivel de consumo que en el pasado les hizo sentirse como pertenecientes a la clase media.

Las otras dos trayectorias incluyen a grupos heterogéneos. En la tercera, la de los inestables estructurales, se encuentran jóvenes, mujeres que han accedido al mercado laboral recientemente, e inmigrantes descualificados. La cuarta, por último, la de los inestables coyunturales, engloba a los trabajadores con nivel de estudios superiores, tanto los que han estado insertados en el mercado de trabajo, como los que están estudiando. Para los pertenecientes a estas dos trayectorias la crisis está teniendo un efecto reformador sobre el mercado laboral, en el sentido de redefinición momentánea; pero que sin embargo les hace mantener una posición ambigua hacia el futuro, por un lado está la incertidumbre de encontrar un empleo que les permita pagar una vivienda y mantener a la familia, y por otro, la actitud optimista de que es posible que las cosas vayan a mejor, sobre todo entre los más jóvenes.

El análisis de estas trayectorias permite, además, dibujar las posibles tendencias hacia situaciones de agravamiento de la pobreza, así como profundizar en el análisis de las estrategias desplegadas para optar a un empleo o conseguir algún tipo de ingresos que permita alejarse de la situación de vulnerabilidad.

El análisis del material discursivo ha permitido complementar la información estadística sobre pobreza, proporcionada por los distintos organismos, con la procedente de las vivencias y percepciones que sobre el efecto de la crisis en el mercado laboral tienen los entrevistados. Los distintos informes mencionados apuntan la importancia que sobre el riesgo de pobreza y exclusión tiene pertenecer a familias con hijos jóvenes, parados procedentes de empleos de baja cualificación (EAPN, 2009), el peso de los excluidos del mercado laboral (Subirats et al., 2004) o de las personas desempleadas como factor de vulnerabilidad (Malgesini, 2013).

A modo de síntesis se puede concluir que los colectivos pertenecientes a las dos primeras trayectorias (estables desestabilizados e inestables desestabilizados) son 
los que mayor tendencia muestran a sufrir un agravamiento de la pobreza. Son los que menos posibilidades tienen de insertarse en el mercado laboral, ya que son poco versátiles al no tener formación y haber desarrollado la mayor parte de su trayectoria en el mismo sector de actividad. Mayores dificultades tienen todavía los inestables desestabilizados: muchas de estas familias sólo cuentan con los ingresos procedentes de alguna prestación, generalmente en torno a 400 euros. Tienen que pedir ayuda para atender las obligaciones familiares, sobre todo a los progenitores, quienes han pasado a ser el soporte fundamental de muchos hogares para afrontar los gastos cotidianos. Además, para estos trabajadores el futuro se muestra mucho más incierto que para el resto, por su edad, y teniendo en cuenta las reformas del Gobierno sobre pensiones, sienten que no van a cumplir los requisitos necesarios para optar a la jubilación remunerada.

La constatación de que los trabajadores estables desestabilizados de la primera trayectoria se encuentren entre los colectivos vulnerables, permite, por último, insistir en el hecho de que la crisis está profundizando la tendencia a borrar las diferencias entre un mercado de trabajo primario con puestos estables y buenos salarios, y un mercado de trabajo secundario en el que los puestos de trabajo son precarios y los salarios bajos.

\section{Bibliografía}

Aragón, J. et al. (2012): Trabajadores Pobres y Empobrecimiento en España. Fundación $1^{\circ}$ de Mayo, Colección Estudios, Núm. 56, 90 pp. Documento electrónico: http://www.1mayo.ccoo.es/nova/NPcd/GestorPublicacionesVis?cod_primaria=1 442\&cod_publicacion=2250. Fecha de acceso: 23/11/2012.

Aragón, J. et al. (2012a): El Tiempo de Trabajo y la Jornada Laboral en España. Madrid: Fundación $1^{\circ}$ de Mayo.

Arrazola, M. de Hevia, J. Mauleón, J. y Sánchez, R. (2011): Estimación del volumen de economía sumergida en España. Cuadernos de Información Económica, Núm. 220, 81-88.

Arriba, A. (coord.) (2008): Politicas y bienes sociales: Procesos de vulnerabilidad y exclusión social. Madrid: Fundación Foessa.

Belzunegui, A. (coord.) (2012): Socialización de la pobreza en España. Barcelona: Icaria.

Borghi, V. (2011): One-way Europe? Institutional Guidelines, Emerging Regimes of Justification, and Paradoxical Turns in European Welfare Capitalism. European Journal of Social Theory, 14 (3), 321-341. 
Brown, P., Hesketh, A., y Williams, S. (2003): Employability in a KnowledgeDriven Economy. Journal of Education and Work, 16 (2), 107-126.

Brown, P., Lauder, H., y Ashton, D. (2011). The Global Auction. The Broken Promises of Education, Jobs and Incomes. Oxford: Oxford University Press.

Cantó, O. (2010) El impacto de la crisis económica sobre los hogares más desfavorecidos, Revista Española del Tercer Sector, Núm. 15, 67-89.

Castel, R. (1997): Las Metamorfosis de la Cuestión Social. Una crónica del salariado. Buenos Aires: Paidós.

Davia, M. A. (2013): Mercado de trabajo y desigualdad. En J. Ruiz-Huerta (Dir.): Primer Informe sobre la Desigualdad en España (pp 75-124) Madrid: Fundación Alternativas. De la Garza Toledo, E. (2009): Hacia un Concepto Ampliado de Trabajo. En J. C. Neffa; E. De la Garza Toledo and L. Muñoz Terra: Trabajo, Empleo, Calificaciones Profesionales, Relaciones de Trabajo e Identidades Laborales, (pp. 111-140). Buenos Aires: CLACSO.

Ebersold, S. (2004): L'Insertion ou la Délégitimation du Chomeur. Actes de la Recherche en Sciences Sociales, 154, 94-102.

Eguía, A. y Ortale, S. (Coord.) (2007): Los significados de la pobreza. Buenos Aires: Biblos.

Fundación Foessa (2013): Análisis y Perspectivas 2013: Desigualdad y derechos sociales. Madrid. Documento electrónico:

http://www.foessa.es/publicaciones_compra.aspx?Id=4556\&Idioma=1\&Diocesis=42. Fecha de acceso: 20/3/2013.

García, I. y Ibáñez. M. (2007): Los trabajadores pobres y los bajos salarios en España: un análisis de los factores familiares y laborales asociados a las distintas situaciones de pobreza. Empiria. Revista de Metodología de Ciencias Sociales. Núm. 14, julio-diciembre, 41-67.

Gutiérrez, R. (2009) La dinámica de pobreza de los trabajadores. Rio. Revista Internacional de Organizaciones, Núm. 3, 49-70.

Laparra, M. (2010): El impacto de la crisis en la cohesión social o el surf de los hogares españoles en el modelo de integración de la "sociedad líquida", Documentación Social, Núm. 158, 97-130.

Lazarsfeld, P., Jahoda, M., Zeisel, H. (1996): Los parados de Marienthal. Madrid: La Piqueta. 
Lee, C. K. and Kofman, Y. (2012): The Politics of Precarity: Views Beyond the United States. Work and Occupations, 39 (4), 388-408.

López, J. J. y Renes, V. (2011): Los efectos de la crisis en los hogares: nivel de integración y exclusión social, Papeles de relaciones ecosociales y cambio global, Núm. 113, 189-199.

Malgesini, G. (Coord.) (2010): Informe anual sobre la vulnerabilidad social 20082009. Madrid: Cruz Roja Española.

Malgesini, G. (Coord.) (2013): Informe sobre la vulnerabilidad social 2011-2012. Madrid: Cruz Roja Española.

Martínez, A. (2011): El Discurso de la Unión Europea en Materia de Políticas de Empleo y Exclusión Social. Análisis Sociológico de la Estrategia Europea de Empleo. Papers, 96 (1), 35-54.

Mauro, A. y Yáñez, S. (2005): Trayectorias laborales y previsión social en Chile en un contexto de flexibilidad. Santiago de Chile: Centro de Estudios de la Mujer (CEM).

Miguélez, F. y Prieto, C. (2009): Transformaciones del Empleo, Flexibilidad y Relaciones Laborales en Europa. Política y Sociedad, 46 (1 y 2), 275-287.

Miguelez et al. (2011): Trayectorias laborales de los inmigrantes en España. Barcelona: Obra Social la Caixa.

Molyneux, M. (2006). La Quimera del Éxito. En Medina, M.C., Domínguez, E. y Garza, R. Género y Globalización en América Latina. Décimo Aniversario de la Red Haina (1996-2006) Vol. Serie Haina Núm. 6. (pp. 11-20). Suecia: Red Haina/ Instituto Iberoamericano, Universidad de Göteborg.

Monereo, J. L. (2003): Las Nuevas Políticas de Protección por Desempleo y su Reflejo en el Sistema Jurídico. Lan Harremanak. Revista de Relaciones Laborales, 73-156.

Navarro, V. (Dir.) (2009): La situación Social en España (Vol.3). Madrid: Biblioteca Nueva.

Piore, M. y Doeringer (1971): Los mercados internos de trabajo. En Toharia, L. El mercado de trabajo: teorías y aplicaciones (pp 341-368). Madrid: Alianza Universidad.

Piore, M. (1983): El dualismo como respuesta al cambio y la incertidumbre. En Toharia, L. (Comp.), El mercado de trabajo: teorías y aplicaciones (pp. 223-254). Madrid: Alianza Universidad. 
Prieto, C. (1994): Mercado de Trabajo y condiciones de empleo: compatibilidad societal y poder social de negociación. Cuadernos de Relaciones Laborales, Núm. 5, 29-40

Prieto, C. (coord.), Arnal, M., Caprile, M. y Potrony, J. (2009): La calidad del empleo en España: una aproximación teórica y empirica. Madrid: Ministerio de Trabajo y Seguridad Social.

Recio, A. (2006): ¿Trabajar evita la pobreza? Bajos salarios en el mercado laboral español, Documentación Social, Núm. 43, 31-43.

Red Europea de Lucha contra la Pobreza (EAPN) (2009): El impacto de la crisis en la pobreza y la exclusión social: diagnóstico y actuaciones. Documento electrónico: http://www.eapn-galicia.com/archivos/606_--el-impacto-de-la-crisis-en-lapobreza-y-la-exclusion-social.pdf. Fecha de acceso: 8/02/2012.

Red Europea de Lucha contra la Pobreza (EAPN) y Centro de Estudios Económicos Tomillo (2011): El impacto de la crisis en la pobreza y exclusión en la Comunidad de Madrid. Documento electrónico: http://www.eapnmadrid.org/?pagina=documentos\&seccion=Documentos. Fecha de acceso: 18/9/2012.

Red Europea de Lucha contra la Pobreza (EAPN) (2012): Las cifras de pobreza y exclusión en España de cara a Europa 2020. Documento electrónico:

http://www.eapn.es/ARCHIVO/documentos/recursos/1/1030_pobreza_exclusion espana.pdf. Fecha de acceso: 13/03/2013

Rodríguez Cabrero, G. (2011): Estudio Comparado sobre Estrategias de Inclusión Activa en los Países de la Unión Europea. Ministerio de Sanidad, Política Social e Igualdad. Documento electrónico: http://www.redinclusionsocial.es/wpcontent/uploads/2013/01/01_Estudio-Comparado-sobre-Estrategias-deinclusion-activa-en-los-paises-de-la-UE.pdf. Fecha de acceso: 3/07/2012.

Salido, O. (2012): Los ciudadanos españoles ante la crisis. Madrid: Fundación Iniciativas para la Paz/Fundación Alternativas.

Sassen, S. (2012): Inequality? We Need a New Word. The Occupied Wall Street Journal. Documento electrónico: http://occupiedmedia.us/2012/02/inequalitywe-need-a-new-word/. Fecha de acceso: 12/12/2012

Schneider, F. (2010): The Influence of the economic crisis on the underground economy in Germany and the other OECD-countries in 2010: a (further) increase. OCDE, Eurostat 2012: Employment and Social Developments in Europe 2012. European Commission Directorate-General for Employment, Social Affairs and Inclusion. 
Serrano, A., Fernández, C. J. y Artiaga, A. (2012): Ingenierías de la Subjetividad: el Caso de la Orientación para el Empleo. REIS, 138 (1), 41-62.

Subirats, J. et al. (2004): Pobreza y exclusión social: un análisis de la realidad europea y española. Colección de Estudios Sociales de la Caixa, Núm. 16. Madrid: Fundación La Caixa.

Vasilachis de Gialdino, I. (2003): Pobres, pobreza, identidad y representaciones sociales. Madrid: Gedisa Editorial.

Villa P. (1990): La estructuración de los mercados de trabajo. Madrid: Ministerio de Trabajo y Seguridad Social.

Wacquant, L. (2008): Urban Outcasts. A Comparative Sociology of Advanced Marginality. Malden MA, Cambridge, UK: Polity Press.

Weishaupt, J. T. (2010): A Silent Revolution? New Management Ideas and the Reinvention of European Public Employment Services. Socio-Economic Review, Núm. 8,461-486.

Zalakin, J. (2006): Trabajo, trabajadores pobres e inserción social. Documentación social, Núm. . 43, 45-76.

Zubero, I. (2006): Las nuevas relaciones entre empleo e inclusión: flexibilización del trabajo y precarización vital, Documentación Social, Núm.43, 11-30. 